my former hypothesis of a stridulating organ." Everybody acquainted with such organs will be of his opinion.

Another insect, Homothetus fossilis, was said to have a small basal vein, considered to be homologous with the arculus of the Odonata, and therefore to form a connecting link between Neuroptera and Pseudoneuroptera. A new synthetic family, Homothetidæ, was proposed. But now a re-examination of this wing convinces the author "that he had been mistaken about this arculus." It does not exist at all.

The third insect, Platephemera antiqua, was determined by me as the apical half of the wing of a gigantic dragon-fly. As this is the only species claimed now by the author to belong to the Ephemeridx, he defends vigorously his determination by four objections:-(I) "In no dragon-fly, living or fossil, is there found beyond the nodus between the mediana and margin, more than a simple longitudinal vein, the marginal vein." If the author will examine any Odonate wing from belowe, he will find such a vein, which is the prolongation of the subcosta, bent on the nodus to the marginal vein, and running close to it. Near the nodus it is more widely separated in larger species. (2) "The reconstruction of the wing, after the dimensions given by Dr. Hagen, would, on the most favourable showing, make a wing of ridiculously extravagant appearance." But such forms occur in living species of Tramea, Rhyothemis, \&c." (3) "The narrowing of the second cubital space is a common feature in Ephemeridæ (six genera after the Rev. Mr. Eaton's plates are quoted) ; and, as this varies in different species of the same genus, it seems to be a very unimportant matter." I had purposely stated suddenly narrowing; and this does not exist at all in Ephemerida, namely not in the six quoted genera, and cannot therefore vary in the different species of the same genus. It exists in Odonata. (4) "The sector subnodalis does not run unbroken to the tip, as in all dragon-flies I have examined, but is lost in reticulation shortly before the margin." This laut-quoted character is a very common feature in dragon-flies (Tramea, Rhyothemis, \&c.). Only very exceptionally this sector runs unbroken to the tip in the large sub-family of Aschnidx (cf. De Selys's "Revue des Odonates d'Europe," p. 122).

As all objections have been proved to be incorrect, and only based upon insufficient knowledge of the venation of Odonata and Ephemeridx, Platephemera belongs by the simple evidence of facts to the Odonata. "The new proposed family of Palephem. eridæ dies unborn, and the conclusions made from Palephemera are without value.

The fourth species, Gerephemera, gives much trouble to the author, and he is now inclined to bring it into the same group with the Protophasmida. As only a part about $4 \mathrm{~mm}$. bioad can be said to exist in both figures (Brongniart and Scudder) which could be compared, and as this part contains only a few sectors running to the maryin, the relationship of Protophasma to Gerephemera is not at all obvious. The reverse of Gerephemera contains more than the author has seen. The basal part of a hind wing to the sector trigonali inferior, the basal part of a front wing with the same sector, and some veins belonging, probably, to another (front?) wing. The part figured and described by the author belongs, probably, to the other hind wing. No student of Odonata will be in doubt that Gerephemera belongs to this family, perhaps near Isophlebia. His statement "that the superior origin of the branches of the sector medius is entirely inconsistent with an Odonate hypothesis, and is the most salient point in the wing," is directly recognised as an error by looking at the figures in De Selys's "Monograph Calopterygines" (cf. Cleis, Vestalis, Neurobasis, \&c.). This statement is only surpassed by the emphatic repetition "that the marginal would then be an elevated, and the mediastinal a depressed, vein, which combination is never the case." This statement is just the contrary to what exists in all Odonata-unless it is preferred to examine the wings from beneath.

There exists still no monograph of the Sialidx; therefore it is impossible to make conclusions and form new families for the other three Devonian species. The opinion on the Devonian insects given by Rev. A. E. Eaton (NATURE, vol. xxiii. p. 507) is still very just: "Palæontologists have adopted a ridiculous course with regard to some insect fossils. Whenever an obscure fragment of a well-reticulated insect-wing is found in a rock, a genus is straightway set up, and the fossil named as a new species. The species is then referred to the Ephemcrida, and is immediately pronounced to be a synthetic type of insects at present distantly related to one another in organisation. This enunciation of synthetic types is often nothing less than a resort at random conjecture respecting the affinities of animals which the writer is at loss to classify. I thought that the Ephem eridae had served quite long enough as an asylum for fossil cripples. I wished to intimate gently, that refuse of other groups of insects should be henceforth shot elsewhere."

Cambridge, Mass., March I 2

H. A. HAGEN

\section{High-Level Stations}

IN NATUKE, vol, xxxii. p. I 7 , I find the abstract of an address by Mr. Omond, on "Ben Nevis." There are many points of interest, but I regret that one was not mentioned-viz. the exceedingly rapid decrease of temperature with elevation from Fort William to the Ben, anything nearly approashing, in middle latitudes, being only found on the Brocken, and all high-level stations of the Alps showing a much smaller decrease. At the Bronken, as well as at the Ben, the great difference from the Alps is not in summer, but in the colder months of the year. The reason seems to lie in the nearly constant winds, which bring air from below, which is cooled by ascension. The cases of great dryness of the air with descending currents in anticyclones in the colder months of the year, when isolated mountains are often much warmer than the valleys, ${ }^{1}$ are comparatively rare in the North of Scotland, but frequent in the Alps, and certainly must and do have a great influence on the mean temperature. Where they are frequent, as in the AIps-especially the eastern-the mean amount of decrease of temperature with elevation must be slower.

I think all meteorologists will concur with me that the greatest points of interest in the Ben Nevis station is the study of the meteorological phenomena near the centres of cyclones, as no hish-level station in the world is s) favourably situated as this for this study.

St. Petersburg, May I (I3)

A. WOEIKOF

\section{Rainbow Phenomena}

Your correspondent Mr. C. Croft (Nature, No. 8i I, p. 3o, has roticed phenomena which are perfectly familiar to students of physical optics. The internal bands of colour within the primary bow are the "supernumerary" bows due to diffraction. They were described by Langwith in the Philosophical Trans. actions for 1722 : a partial theory of them was given by Young in $\mathbf{1} 804$, and a complete theory by Sir G. Airy in 1836 . The illu mination of the sky in the regions within the primary and with. ont the secondary bows, and also the relative darkness of the space between the two bows, Mr. Croft will find the desired explanation in any elementary treatise on optics ; Osmund Airy's Geometrical Optics may be cited as giving a good account of thesc matters. The particular bow seen by Mr. Croft appears to have been of unusual brilliancy; did he notice any of the radial streaks, which I described in 1878 as frequently accompanying rainbows?

Finsbury Technical College, May I6

\section{Aurora}

LAST night at about 10.30 to $10.35 \mathrm{p.m}$. there was a wellmarked aurora visible from here. It did not last long, the bright bands fading rapidly into a general glow towards the north. The wind, which was easterly yesterday, has gone round to north-west to-day with tendency to rain and low temperature.

Royal College of Science for Ireland, Stephen's J. P. O'REILLY Green, Dublin, May I4

\section{Red Hail}

Mr. W. H. Mitciiel, of Newry, has sent me the accompanying note, which he thinks may be of interest to the readers of NATURE.

Downshire Hill, Hampstead, N.W'., May I8

On May 7, Mr. R. A. Mullan, solicitor, of Newry, was driying in a gig near Castlewellan, co. Down, when he was overtaken by a shower of hail. To his surprise he observed that some of the hail-stones-perhaps one in a hundred-were of a ${ }^{x}$ This is well explained in the "Handbuch der Climatologie" of T. Hann. See also my paper in the Zeitschr. f. Meteorologie, $\mathbf{1 8 8} 3$, pp. $2 \mathrm{Ir}, 24 \mathrm{I}$. 